\title{
Long Course preface: pathology of liver and pancreas
}

\author{
Modern Pathology (2007) 20, S1-S2. doi:10.1038/modpathol.3800681
}

The Long Course at the US and Canadian Academy of Pathology Annual Meeting was first instituted in 1953 by the Program Committee (currently known as the Education Committee). The general purpose of the course was to focus on an organ system in some depth, with rotation of the topics from year to year (Table 1). The USCAP News Bulletin at that time stated 'It has been suggested that in addition to the general meeting our association offer a one day course in pathologic physiology. For example, under such a plan a course may be offered on the kidney, the lung or other organ, with 6-8 outstanding speakers invited to discuss its anatomy and embryology, its physiology, and the morphologic changes in disease, and perhaps even clinical and experimental aspects. This would not be a seminar, nor would microscopic slides be used. The course would not duplicate those offered by any other society and would extend and supplement the program. It would have the advantage of a thorough review of an organ not only with regard to its diseased state but its normal function as well. Whether such a course can be offered at the 1953 meeting remains to be seen, but if the members are interested the Program Committee will make every effort to arrange for it.' This idea was fostered by Dr FK Mostofi, who was the Secretary-Treasurer, and carried out at the April 1, 1953 meeting in St Louis. The Secretary's News Letter, Vol. 1, No. 3 dated January 1954 stated: 'The pattern established at the 1953 meeting will be followed. It is appropriate to acknowledge that much of the success of last year's course was owed to the vigorous efforts of our excellent secretary, Dr Mostofi.'

The course quickly became a popular part of the program for the Annual Meeting, and soon after, the Long Courses were published as separate Monographs in Pathology (Williams and Wilkins, Publisher) through the 1996 course. In 1997, the Breast course was the first to be published as a Supplement to Modern Pathology. We are now presenting the 2006 Long Course on Liver and Pancreas.

Liver Pathology was first selected for the topic in 1954, and was the second topic chosen (obviously following lung in the order of importance to the membership, or so we, as the two course directors,

Table 1 USCAP Long Course topics ${ }^{\mathrm{a}}$

\section{Year Topic and director(s)}

1953 Pathologic Physiology of the Lung - Wiley D Forbus

1954 Pathologic Physiology and Surgical Pathology of the Liver-Edward A Gall

1955 Pathologic Physiology and Pathology of the Heart - Jesse E Edwards

1956 Pathologic Physiology and Pathology of the Erythropoietic Series - Israel Davidsohn

1957 Pathologic Physiology and Pathology of the Skin - Elson B Helwig

1958 Pathologic Physiology and Pathology of the Bone - Granville A Bennett

1959 Pathologic Physiology and Pathology of the Lymphocytes and Lymphocytic Tissue - John W Rebuck

1960 Pathologic Physiology of the Adrenal Cortex - Henry D Moon

1961 Pathologic Physiology and Anatomy of the Ovary - Hugh G Grady

1962 Pathologic Physiology and Anatomy of the Peripheral Vessels - J Lowell Orbison

1963 Pathologic Physiology and Anatomy of the Thyroid - JB Hazard

1964 Pathologic Physiology and Anatomy of the Kidney - FK Mostofi

1965 Pathologic Physiology and Anatomy of Connective Tissue - Bernard M Wagner

1966 Pathologic Physiology and Anatomy of the Lung - Averill A Liebow

1967 Pathologic Physiology and Anatomy of the Central Nervous System - Orville T Bailey

1968 Pathologic Physiology and Anatomy of the Skin - Elson B Helwig

1969 Pathologic Physiology and Anatomy of the Platelet - KM Brinkhous and NF Rodman

1970 Pathologic Physiology and Anatomy of the Striated Muscle - Carl Pearson

1971 Pathologic Physiology and Anatomy of the Liver - Edward A Gall

1972 Pathologic Physiology and Anatomy of the Uterus - Arthur T Hertig and Henry J Norris

1973 Pathologic Physiology and Anatomy of the Heart - Jesse E Edwards and Maurice Lev

1974 The Reticuloendothelial System: Function, Reaction and Neoplasia - John W Rebuck and Coston W Berard

1975 Diseases of Bones and Joints - Lauren V Ackerman and Harlan J Spjut

1976 Inflammatory and Neoplastic Diseases of the Gastrointestinal Tract - John H Yardley and Basil C Morson

1977 Recent Advances in Pulmonary Pathology - William M Thurlbeck

1978 Kidney Diseases - Present Status - Jacob Churg, Benjamin H Spargo and FK Mostofi

1979 The Pancreas - Patrick J Fitzgerald and Ashton B Morrison

1980 Perinatal Diseases - Richard L Naeye and John M Kissane

1981 The Inflammatory Process and Infectious Diseases - Guido Majno and Ramzi S Cotran

1982 Connective Tissue and Diseases of Connective Tissue - Bernard M Wagner and Raul Fleischmajer

1983 The Breast - Robert W McDivitt, Harold A Oberman and Luciano Ozzello

1984 The Pathologist and The Environment - Dante G Scarpelli and John Craighead 
Table 1 Continued

\begin{tabular}{|c|c|}
\hline Year & Topic and director(s) \\
\hline 1985 & The Pathogenesis of Liver Diseases - Emmanuel Farber and M James Phillips \\
\hline 1986 & $\begin{array}{l}\text { Malignant Lymphoma, Leukemia and The Immune System: From Cacophony to Clarity - Costan W Berard and } \\
\text { Ronald F Dorfman }\end{array}$ \\
\hline 1987 & Pathobiology and Recognition of Malignant Melanoma - Martin C Mihm Jr and George F Murphy \\
\hline 1988 & Gastrointestinal Pathology - Harvey Goldman and Henry Appelman \\
\hline 1989 & Neuropathology Today - Pasquale A Cancilla and F Stephen Vogel \\
\hline 1990 & The Pathology of Reproductive Failure - Frederick Kraus and Ivan Damjanov \\
\hline 1991 & Genitourinary Pathology with Focus on Prostate and Bladder - Ronald S Weinstein and William A Gardner \\
\hline 1992 & Thyroid and Parathyroid Glands - Virginia LiVolsi and Ronald DeLellis \\
\hline 1993 & Pulmonary Pathology - Andrew Churg and Anna Luise Katzenstein \\
\hline 1994 & Cardiovascular Pathology - Michael Gimbrone and Frederick Schoen \\
\hline 1995 & Soft Tissue Pathology - Sharon W Weiss and John SJ Brooks \\
\hline 1996 & Errors and Pitfalls in Diagnostic Cytology - Leopold G Koss and James Linder \\
\hline 1997 & Breast - David Page and Fattaneh Tavassoli \\
\hline 1998 & Hematopathology - Elaine Jaffe and Cheryl Willman \\
\hline 1999 & Pathology of the Uterine Corpus and Cervix - Steven Silverberg and Mark Sherman \\
\hline 2000 & Pathology in the New Millineum - Sylvia Asa and Allen Gown \\
\hline 2001 & Tumors of the Head and Neck - Stacey Mills and Richard Zarbo \\
\hline 2002 & Gastrointestinal Pathology - Donald Antonioli and Robert Petras \\
\hline 2003 & Prostate Cancer Pathology and Pathobiology - Jonathan I Epstein and Peter A Humphrey \\
\hline 2004 & Gonadal (Ovarian and Testicular) Pathology - Robert H Young and Thomas M Ulbright \\
\hline 2005 & Neoplastic Dermatopathology - Bruce R Smoller and A Neil Crowson \\
\hline 2006 & Liver and Pancreas - Linda D Ferrell and N Volkan Adsay \\
\hline 2007 & Targeted Therapy of Cancer: New Roles for Pathologists - Marc Ladanyi and Allen M Gown \\
\hline
\end{tabular}

${ }^{\mathrm{a}}$ Liver and pancreas-related topics in bold.

would like to think!!). Since that time, the liver has been a topic two times, in 1971 and 1985. Pancreas did not make it on the list until 1979 (so has been somewhat neglected by our 'unbiased' analysis). Thus, this course provides a timely update for both of these organs for our academy members.

As course directors, we knew that we could not comprehensively cover all the medical and neoplastic entities involving these two organs in the time allotted, and so we have tried to narrow the topics to major areas that we thought would be of interest to most practicing pathologists. For the liver, we have focused on areas of diagnostic difficulty, as well as topics with compelling recent developments or important changes since the previous courses. For the pancreas, we have attempted to highlight the most important diagnostic aspects and recent developments in the study of pancreatic neoplasia and pancreatitis. Thus, the articles in this supplement are meant to represent a focused, expert approach to problem areas in diagnostic pathology of the liver and pancreas and to provide recent and up-to-date perspectives on some of the issues rather than exhaustive reviews of the literature.

The course directors would like to thank our faculty (Drs Batts, Brunt, Goodman, Hruban, Klimstra, Kloeppel, Theise, and Washington) for their efforts in preparation of the course, for their excellent presentations at the course in Atlanta, and in preparing these final manuscripts. We think the faculty have done an outstanding job, and greatly appreciate their hard work and timeliness in this regard. We would also like to show our great appreciation for the hard work of the USCAP office personnel including JoAnn Johnson, James Crimmins, Kerry Crockett, and Dr Fred Silva for their efforts in helping to bring this course and this supplement together. Of special note, we express thanks to JoAnn Johnson for her help collecting the history of the Long Courses for this preface.

Finally, the faculty and course directors would like to dedicate this supplement to the memory of three pathologists who contributed significantly to the study of liver or pancreas pathology: Peter Scheuer, Kamal Ishak, and Patrick Fitzgerald. Much of our current practice in the areas of liver and pancreas pathology can be traced back to these three outstanding pathologists, and we would like to remember them for their lifelong dedication and contributions to the study of liver or pancreatic pathology, their devotion to teaching and mentoring many of the younger generation of pathologists in their respective fields, and for the leadership they provided for us all. We'll miss them.

Linda D Ferrell ${ }^{1}$ and N Volkan Adsay ${ }^{2}$

${ }^{1}$ Department of Anatomic Pathology, University of California San Francisco, San Francisco, CA, USA and ${ }^{2}$ The Karmanos Cancer Institute and Wayne State University, Detroit, MI, USA 